E International

\title{
Travel Behaviour Response to Major Transport System Disruptions
}

Implications for Smarter Resilience Planning

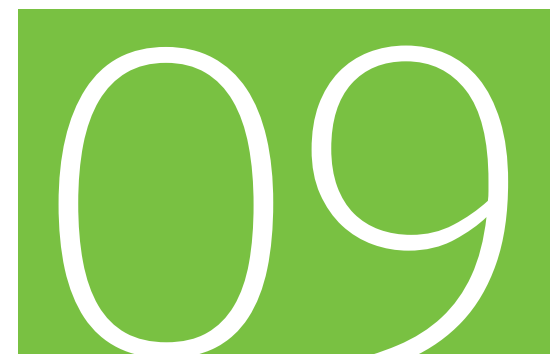

Discussion Paper 2016•09

Greg Marsden, Jillian Anable, and Jeremy Shires

University of Leeds, United Kingdom

Iain Docherty

University of Glasgow, Scotland,

United Kingdom 


\title{
EInternational Transport Forum
}

\section{Travel Behaviour Response to Major Transport System Disruptions}

\section{Implications for Smarter Resilience Planning}

\author{
Discussion Paper No. 2016-09
}

\author{
Prepared for the Roundtable on \\ Preparing for Major Disruptions to Transport Systems
}

(19/05/2016, Leipzig)

Greg Marsden, Jillian Anable, Jeremy Shires

Institute for Transport Studies, University of Leeds, Leeds, UK

Iain Docherty

Adam Smith Business School, University of Glasgow, Glasgow, UK

May 2016 


\title{
The International Transport Forum
}

The International Transport Forum is an intergovernmental organisation with 57 member countries. It acts as a think tank for transport policy and organises the Annual Summit of transport ministers. ITF is the only global body that covers all transport modes. The ITF is politically autonomous and administratively integrated with the OECD.

The ITF works for transport policies that improve peoples' lives. Our mission is to foster a deeper understanding of the role of transport in economic growth, environmental sustainability and social inclusion and to raise the public profile of transport policy.

The ITF organises global dialogue for better transport. We act as a platform for discussion and pre-negotiation of policy issues across all transport modes. We analyse trends, share knowledge and promote exchange among transport decision-makers and civil society. The ITF's Annual Summit is the world's largest gathering of transport ministers and the leading global platform for dialogue on transport policy.

The Members of the Forum are: Albania, Armenia, Argentina, Australia, Austria, Azerbaijan, Belarus, Belgium, Bosnia and Herzegovina, Bulgaria, Canada, Chile, China (People's Republic of), Croatia, Czech Republic, Denmark, Estonia, Finland, France, Former Yugoslav Republic of Macedonia, Georgia, Germany, Greece, Hungary, Iceland, India, Ireland, Israel, Italy, Japan, Korea, Latvia, Liechtenstein, Lithuania, Luxembourg, Malta, Mexico, Republic of Moldova, Montenegro, Morocco, the Netherlands, New Zealand, Norway, Poland, Portugal, Romania, Russian Federation, Serbia, Slovak Republic, Slovenia, Spain, Sweden, Switzerland, Turkey, Ukraine, the United Kingdom and the United States.

\author{
International Transport Forum \\ 2 rue André Pascal \\ F-75775 Paris Cedex 16 \\ contact@itf-oecd.org \\ wWw.itf-oecd.org
}

\section{ITF Discussion Papers}

The ITF Discussion Paper series makes economic research, commissioned or carried out in-house at ITF, available to researchers and practitioners. They describe preliminary results or research in progress by the author(s) and are published to stimulate discussion on a broad range of issues on which the ITF works. Any findings, interpretations and conclusions expressed herein are those of the authors and do not necessarily reflect the views of the International Transport Forum or the OECD. Neither the OECD, ITF nor the authors guarantee the accuracy of any data or other information contained in this publication and accept no responsibility whatsoever for any consequence of their use. This document and any map included herein are without prejudice to the status of or sovereignty over any territory, to the delimitation of international frontiers and boundaries and to the name of any territory, city or area. Comments on Discussion Papers are welcome. 


\section{Funding and Acknowledgements}

The research reported here is from the Disruption: the raw material for low carbon change project (www.disruptionproject.net), funded under the RCUK Energy Programme, ESPRC Award No EP/J00460X/1. Data from the Forth Road Bridge was collected in collaboration with Transport Scotland and funded through the Universities of Leeds and Glasgow EPSRC and ESRC Impact Acceleration Accounts. The authors would like to thank James Faulconbridge, Lesley Murray, Tim Chatterton and Helen Roby for their valuable inputs to the Disruption project. 


\section{Table of contents}

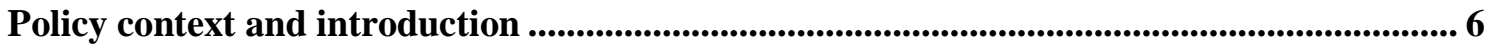

Engineering resilience, societal resilience and the economics of resilience .............................. 7

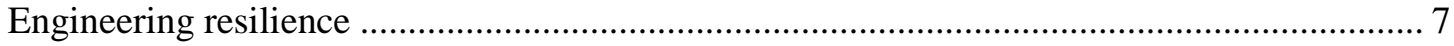

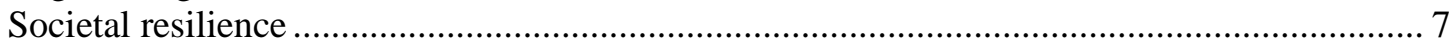

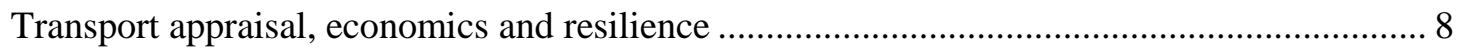

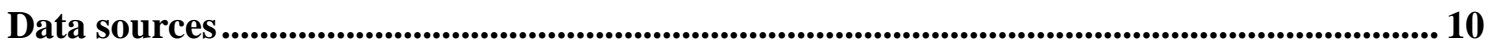

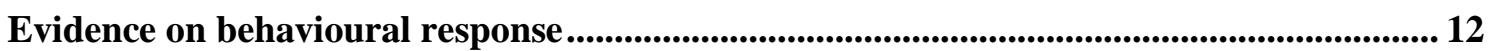

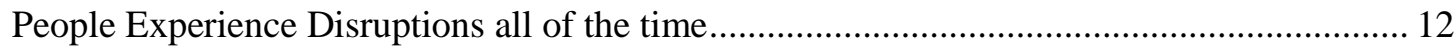

For short-run disruptions there is a lot of adaptive capacity .................................................. 15

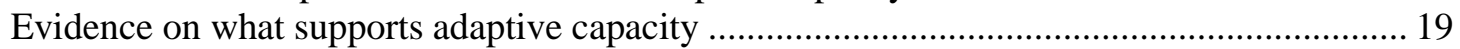

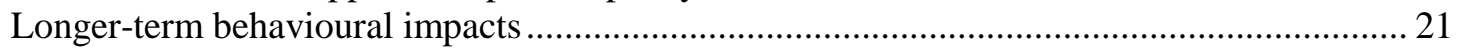

Information ........................................................................................................................................ 22

Implications for resilience planning ...................................................................................... 23

A smart resilience strategy is a combination of transport and non-transport responses .......... 23

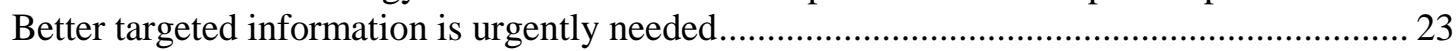

The skills needed for resilience response are the skills needed to promote more sustainable travel and these need to be put together ................................................................. 24

The economic impacts of disruptive events need re-examining as does the basis for

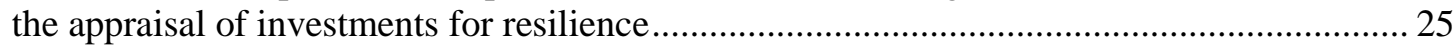

Bibliography ................................................................................................................................................... 26 


\begin{abstract}
The current focus of transportation policy around disruptive events is to adopt an engineering resilience-oriented approach, which focuses on returning assets to good workable order as soon as possible. This will remain critically important in the future to reduce the scale and severity of disruptive events which are likely to become more commonplace in many locations due to climate change. It is, however, only one part of ensuring that such events have more limited impacts on society and the economy. A broader consideration of societal resilience and responses outside the transport sector is needed. People travel in order to take part in activities (work, education, caring and so on), and a smarter resilience response requires us to better understand these activity patterns and intervene accordingly. There is significant adaptive capacity within society that could be better harnessed to reduce the impacts of disruptive events.

The work also shows that many of our assumptions about the short and long run impacts of disruptive events need re-examining to get a fuller picture of the true economic effects of disruptive events on society and the economy. Without this it will be difficult to make the case for many types of resilience investment.

This briefing paper presents evidence collected from new studies of behavioural adaptation during disruptive events and uses this to identify four areas for action to improve how we plan for resilience and how we assess the worth of different types of investment strategy:

1. The development of Smart Resilience Strategies - which are a combination of transport and non-transport responses which work together to minimize the impacts of temporary infrastructure loss;

2. Measures to improve the usefulness, impact and co-ordination of communications with the public and businesses during disruptions, enabling social adaptation and reducing time wasted in unnecessarily perilous and extended journeys;

3. A continued programme of developing the capacity of travellers and businesses to adapt to different events through greater multi-modality and an increase in smart and flexible working practices; and

4. A reassessment of the approach to understanding the economic impacts of disruptive events which extends well beyond the apparent reductions in flows and increases in journey times observed on the networks and captures the societal and economic impacts in a more holistic way.
\end{abstract}




\section{Policy context and introduction}

There is global recognition that climate change will impact on the "operation, financial, environmental and social performance" of infrastructure (EC, 2013). As previous reports by the International Transport Forum (ITF) show, the impacts will vary in different parts of the world but they will also be uncertain and difficult to predict (ITF, 2015). Much work is already underway by asset managers and service operators to understand current and potential future vulnerabilities and to change the way they manage their assets and investment plans to reduce these vulnerabilities (e.g. Volpe, 2015; DfT, 2015).

Even with the most comprehensive plans in place, there is an acceptance that some degree of asset failure is inevitable given the scale and range of vulnerabilities. For example, the UK rail network operator estimated that $12 \%$ of its delays over the period since 2006 were a result of seasonal and weather-related events. Given the inevitability of disruption there is, therefore, a need to "focus on minimising the consequences of asset failure" (ITF, 2015). This has typically been considered as reducing the time it takes to put infrastructure back into usual working order, thereby removing the cause of the negative economic and social impacts. For example, in recent winter flooding at Gatwick Airport and the Port of Immingham in the UK, the loss of power and IT servers as part of the floods delayed the return of the assets to full operational conditions beyond the time it took to make the physical infrastructure serviceable again (DfT, 2014). These additional vulnerabilities can be identified and removed, sometimes at relatively low cost.

This discussion paper looks at a third part of the response strategy which relates to better understanding the wider societal impacts on travellers, how they can and do respond to such events and, therefore, how agencies might implement better smarter disruption management plans. While network managers and service operators are important players in such an approach, the wider societal impacts relate to how business, healthcare and education establishments etc. respond to these events. Although improved information from transport organisations to travellers is part of this (ITF, 2015), issues such as working practices, broadband provision and temporary reconfiguration of how things are done in both the public and private sector are also important.

A greater understanding of the broader societal impacts of such events is also important because "the economic rationale for investing in transport resilience is currently poorly developed and needs to be strengthened. Infrastructure operators in particular need to develop methodologies for estimating the economic and social costs of disruption" (DfT, 2014). Only by understanding the real societal impacts of these events can the case effectively be made for different levels of resilience spending so that investment can be effectively targeted.

This discussion paper explores these issues as follows. In the next section, the assumptions underpinning the current practice of assessing resilience investments are explored. Next, the data on which the findings of this paper are based are introduced. The main analysis of key societal responses derived from the data are then presented before the paper identifies key conclusions and actions which will make for better preparedness for major transport disruptions in the short and long run. 


\section{Engineering resilience, societal resilience and the economics of resilience}

\section{Engineering resilience}

Engineering and economics are arguably the dominant disciplines in transport research and policy formation and these framings strongly steer the current approach to climate adaptation thinking in the sector. Engineering resilience looks at the availability or functionality of physical assets. It is straightforward to conceptualise breakdown or disruption to a physical system such as a bridge which might be closed for repairs or some rail track which is washed away in flooding (Zhu and Levinson, 2010).

The engineering resilience approach is reinforced, in part, by how our transport systems are governed. Systems of transport provision are often organised around modal infrastructure (road, rail, ports or airports) and these systems are generally organised or regulated around the availability of infrastructure. It is what owners and operators of infrastructure can be held to account for. Resilience in this context is often interpreted as putting back affected infrastructure to the agreed level of service following an incident (Quarmby, 2010). This is aligned with thinking from the field of engineering/operational resilience in which the two principal objectives are to stop disruptions happening in the first place, and if they do, to return the mode/service in question to full "normal" operation as quickly as possible (Holling, 1986; Figliozzi and Zhang, 2010; Begg et al., 2011). Here the disruption is to the asset and disruption is seen as being relative to some pre-determined engineering level of service (e.g. availability or capacity). Where it is considered, the use of the asset is factored in typically through consideration of volumes of traffic or volumes of "economically important traffic" typically using the asset. The severity of the impact of the asset failure is estimated through models or assumptions about the uniqueness of the asset and the extent to which alternative routes are available and at what delay and financial cost to the user. There is little attention paid to wider economic impacts neither beyond traveller delays nor of alternative adaptive responses that might occur across the economy.

\section{Societal resilience}

The societal resilience approach considers the impacts of disruption as being to the system of activities that depends on the infrastructure in question. Given that systems of activities develop over time, this means that their functioning often depends on the presumption that particular infrastructure will be available (Mattson and Jenelius, 2015). Although not specifically considering travel, Vollmer (2013: 2) focuses his insights around the key notion that what is disrupted by events is the "coordination of activities and expectations" within a collective entity. It is therefore not just the potential impact of disruption on an individual making a journey, but on the wider social systems of co-ordination (e.g. the dynamics of a work meeting involving participants from different branch offices, or a sports team having sufficient numbers to play) that we need to explore and understand to capture the real impacts of disruption. For example, we know that encouraging more people to work from home would be one way of reducing the potential negative impacts of infrastructure closures in an area. The extent to which this is possible is defined by what infrastructure is in place to support home working, the structure of employment in an area and what proportion of the population could home work. However, it is not just the potential to work from home but the "expectations" or "social norms" which, for example, shape how 
acceptable it is to be late during these incidents or whether staff feel their employers support greater home working or flexing of their shift work during these periods.

A final observation on the importance of a broader societal resilience approach is to note that this also allows for the long-term impacts of disruptions to be considered. As Graham and Thrift (2007: 5) note, recovery is the means by which society "produces learning, adaptation and improvisation." If we only look at infrastructure then, once the infrastructure is repaired, the system returns to its previous level of service. However, people adapt and change their behaviours in response to disruptions (see the section on evidence on behavioural response) so, whilst the infrastructure may return to normal, some aspects of the underlying behaviours do not. Similarly, longer-term "expectations" may change. For some infrastructure it may become to be seen as normal that it is closed for several days in any particular winter (e.g. ferries or bridges due to high winds) and social adaptations are put in place to adapt to that (e.g. levels of stock holding in businesses). People may also now choose to live in places which are vulnerable to some transport disruption that they previously would not have if they know they can occasionally work from home to mitigate the consequences of relatively infrequent events. A key question for understanding the economic impacts of disruptive events is to what extent does repeated unreliability (and at what level) begin to make a difference to the attractiveness of places for inward investment? This again requires us to look beyond just the engineering outcomes.

\section{Transport appraisal, economics and resilience}

There have only been a handful of attempts to evaluate the costs of disruptions to the transport network caused by such low frequency, but high impact events, as well as the benefits of policies that minimise the impacts of such disruptions. The costs of freeway closures due to the 1994 Northridge earthquake in Los Angeles are estimated to have exceeded USD 1.6 million per day (Wesemann et al., 1996), with the cost of the 2007 Minneapolis I-35W bridge collapse estimated to be between USD 71000 and USD 220000 per day (Xie and Levinson, 2011). The range of estimates is produced by different assumptions about traveller response and other calculations such as the value of time. However, the science here is under-developed (DfT, 2014) and it is only now, with the kind of evidence presented in this paper that we are beginning to understand the real impacts of these events on users and the wider economy.

Laird et al. (2014) set out a series of challenges to the standard approaches adopted within transport appraisal which suggest that a new or significantly adapted set of techniques will be required to assess disruptive events and the worth of resilience interventions:

- Some of the core assumptions in estimating costs and benefits are violated during periods where there are very large increases in journey times and complete losses of a mode. For large changes in travel costs, for example the linear assumption of a demand curve can lead to an overestimation of the use costs, while the complete loss of a mode makes traditional calculations intractable;

- We have relatively limited understanding of the marginal costs of disruption beyond single day events. Values of lateness can be up to seven times the value of in-vehicle time (Wardman, 2001). However, it is not clear that such valuations hold during periods of extended disruption where users' expectations of the normal running of the network are also changed. Supply chains may also become disproportionately impacted over time, dependent on stock holding levels for example. It cannot be assumed that the impacts remain the same over time. The impacts on the case for investment here are currently uncertain; 
- Transport appraisal only looks at impacts within the transport market. Whilst it can be the case that some disruptive events can be contained to just the transport system - for example transport closures of several hours due to fatalities on a railway line or a road - large parts of a local or regional economy can be affected by some disruptive events. School closures and leisure facility closures explain some of the drops in traffic levels and properties and businesses are flooded, all of which influence the change in traffic levels we observe. Transport is, in such cases, a secondary and not primary market. To understand the real impacts of these events would require the adoption of multiple market models (e.g. general equilibrium modelling). The current approach to understanding impacts is likely to be an underestimate of total costs.

- Strategies of risk minimisation are also neglected and are hidden costs in the engineering resilience approach: for example businesses which keep additional stocks for disruptive events or adults who work less than they otherwise might to ensure childcare arrangements are robust. These examples of risk adverse behaviour imply firstly the likely existence of option values and secondly a potential shift in the long run supply curve with disruption (e.g. increased inventories both for households and businesses). The extent of these option values and risk minimising behaviours are not understood, nor is the balance between additional state expenditure on providing guarantees of particular levels of service and the expenditure which could then be foregone on such measures. The current approach is likely to underestimate some of these costs.

It can be very difficult to justify expenditure on the grounds of resilience for some parts of the network because such events can be rare but high impact. Across the life of the assessment period of 40 to 60 years the benefits of such events can be small relative to the daily benefits of congestion reduction and environmental improvement for example. Whilst the ideal is to design resilience into all new schemes, the reality is that large parts of our networks are aged and already exposed to these risks and the risks are growing. The case for intervening needs to be made, we suggest, on a clearer whole system understanding of the impacts of these events and it is necessary to look at the decision-making toolkit which underlies this.

In this paper therefore, we explore evidence which considers not just the direct transport system responses as measured by flows, diversions and journey times but also the broader societal response. By broadening our field of interest we will also come closer to understanding the full social costs of adaptation during disruption. 


\section{Data sources}

The evidence reviewed in this paper consists of large sample surveys of:

- A major snow and ice event in 2013 lasting over two weeks which led to the closure of motorways and airports as well as many minor roads. $\mathrm{N}=2417$.

- A major flooding event in 2014 across the south east of England which closed roads and rail lines for several days. $\mathrm{N}=520$. This is augmented by in-depth qualitative research of flooding in the historic city of York (2012).

- The closure of the Forth Road Bridge in Scotland to all traffic for three weeks in December 2015. We have a large sample survey of travellers $N=1364$ alongside data from traffic count sites and a smaller survey of affected businesses.

- A large sample survey $\mathrm{N}=2700$ of six areas of the UK seeking to understand adaptive capacity amongst travellers.

There are two important aspects to note about these data sets. First, for the three data sets collected on actual disruptions, these were all collected during the period of the disruption itself. Almost all of the data in the literature to date has been generated from travellers' post hoc reflections, which are inevitably subject to significant recall issues and response bias.

Second, the data covers a range of circumstances in a range of contexts within the UK. The Forth Road Bridge closure was a clearly defined infrastructure failure where there was a government agency tasked with managing that failure and implementing a response plan. The flooding research covered a large area of Southwest England. The flooding affected a large number of road and rail routes in the area for, in some cases, several weeks. However, there were also parts of the network which were not affected. The winter weather survey was conducted over several of the worst affected areas of England and Scotland. The impacts varied day to day with the weather but the freezing temperatures meant that large areas were impacted for one or two weeks with much less clarity over exactly where in the network impacts would occur. Taken together they provide an interesting set of responses and we pick out commonalities but also differences which relate to each type of incident. It is not the intention here to suggest that the UK data is representative of other contexts but rather to identify themes which could be expected to be evident in a range of places. Further evidence from other sources also collected during the disruptions is used to reinforce this where it is available.

Data collection for the snow/ice and flooding surveys took the form of online panel surveys which sampled from the UK's largest commercial panel of respondents as maintained by the market research company Research Now. Specific geographical and socio-economic quotas were put in place to ensure that both surveys were statistically representative for the regions being surveyed. In practice this resulted in a number of screening questions being asked of prospective respondents to ensure that only "in-scope" respondents were included in the survey. A pilot "soft launch" took place prior to the main surveys in order to sense check responses and to test the technical functioning of the online surveys. It was 
important that the surveys were undertaken whilst the disruptions were underway in order to capture respondent's real time responses rather than rely on recollection. The size of the commercial panel enabled a large number of respondents to be contacted within a short space of time.

A different approach was taken when collecting data for the Forth Road Bridge closure survey. An online panel approach was initially considered, however discussions with Research Now and other panel providers surmised that it would be difficult and extremely costly to obtain a sizeable in-scope sample. Instead a mixed-mode approach was developed which utilised: (1) an online survey promoted via Twitter; (2) a postal survey mailed directly to 9500 households in areas affected by the disruption; and (3) the distribution of self-complete paper surveys to passengers boarding train services operating across the Forth Rail bridge and to passengers boarding direct coach services at a park and ride site travelling to Edinburgh via an alternative bridge with a significant detour.

In addition, a questionnaire was designed to provide an overview of public perceptions of disruption and how they are experienced and managed. This was administered in six different "Travel to Work Areas (TTWA)" in the UK in September 2013. TTWA are statistically derived geographical regions based on UK Census data that describe self-contained labour markets where at least $75 \%$ of the area's resident workforce also works in the area and at least $75 \%$ of the people who work in the area also live in the area. Once again a market research company was used to provide an online sample (in this case YouGov) and age and gender quotas were applied to ensure a representative sample with additional corrective weights applied among the 2700 final respondents. 


\section{Evidence on behavioural response}

This section presents some headline findings which emerge from the various different sources of data. The response set open to people during the closure of one or several stretches of major infrastructure is, typically, the same set which people use when their journey goes wrong or they need to do things differently on any other day. They need to decide whether to:

- $\quad$ continue to do the activity;

- $\quad$ continue to the same destination to do that activity or change it;

- $\quad$ continue to use the same mode of transport and route or change it;

- $\quad$ continue to make the journey there and back at the same time or vary this;

- $\quad$ re-organise the activity for another day and do something else;

- $\quad$ cancel the activity altogether and do something else.

Various combinations of these may be adopted for any one trip. Over the course of days and weeks, different combinations may be deployed (for example travel to work on fewer days and go by train instead of car when travel cannot be avoided).

\section{People Experience Disruptions all of the time}

Our data suggests that dealing with disruption to travel patterns is a fairly normalised part of life. Many people experience regular disruption and therefore have already developed some strategies for how to respond to it. Figure 1 below from the six city survey shows that just over 1 in 10 people deal with a disruption each week as part of their everyday life.

Whilst everyday roadworks are a major source of disruption to journeys, people report having to change and adapt how they travel for a wide range of reasons as shown in Table 1. Just over $50 \%$ of respondents had been affected by at least one of these events in the last month. In the past year, $60 \%$ of respondents reported having been affected by bad weather. 
Figure 1. Frequency with which everyday activities are disrupted (Six City Survey, N=2 700 (weighted))

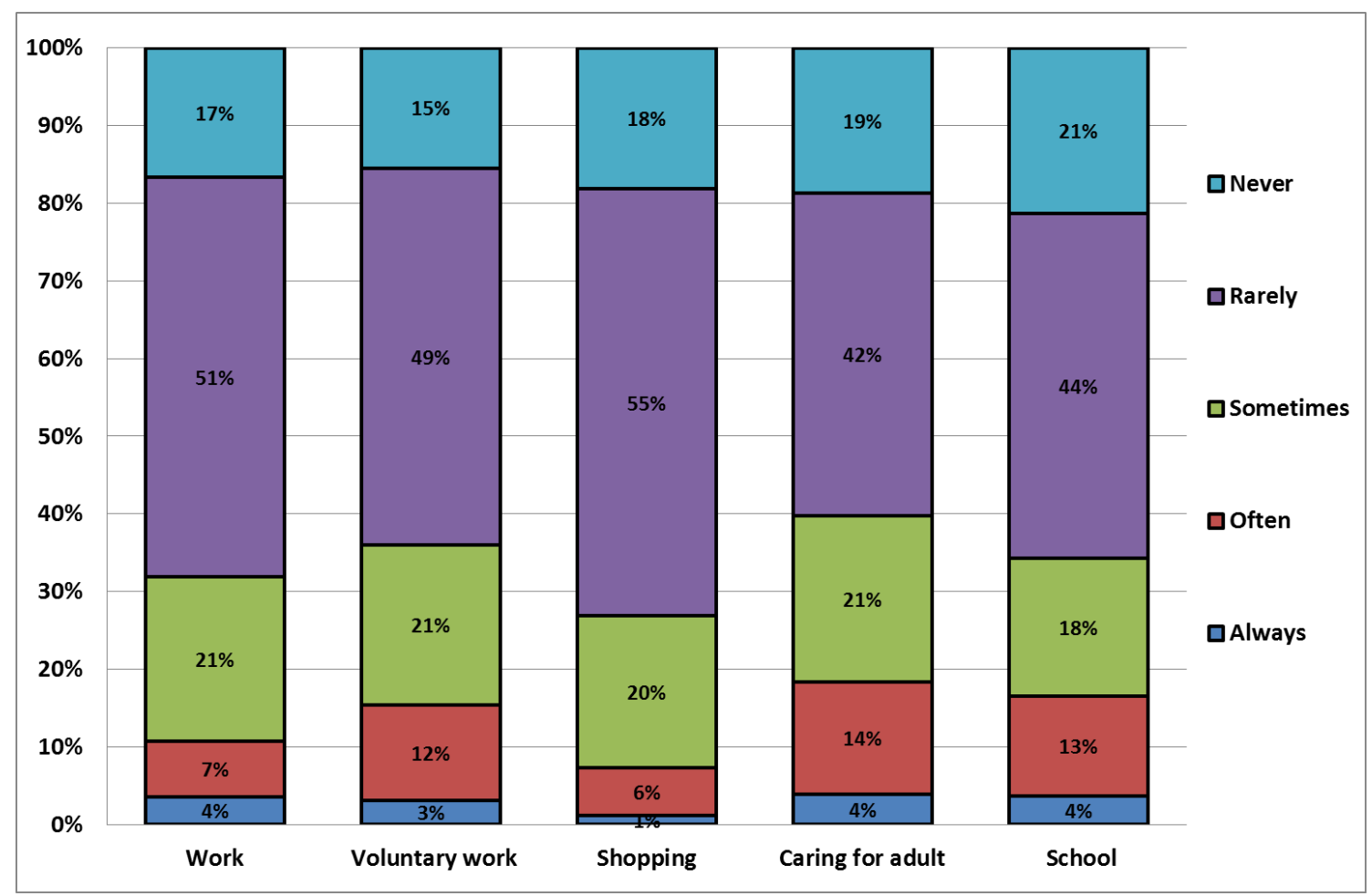

In an open question, respondents were asked to report "the type of events that cause the greatest amount of disruption in your life that cause you to have to do something differently to what you were expecting to do." The results revealed that disruptions originating from the transport system or weather are responsible for only just over half of these events (Figure 2).

Table 1. Experience of different disruptive events

\begin{tabular}{|l|r|r|r|r|r|}
\hline $\begin{array}{l}\text { When was the last time (if at all) your daily } \\
\text { activities were disrupted by the following types } \\
\text { of events? }\end{array}$ & $\begin{array}{l}\text { Within } \\
\text { the past } \\
\text { month }\end{array}$ & $\begin{array}{l}\text { More } \\
\text { than a } \\
\text { month } \\
\text { ago, but } \\
\text { within } \\
\text { the past } \\
\text { year }\end{array}$ & $\begin{array}{l}\text { More } \\
\text { than a } \\
\text { year ago, } \\
\text { but } \\
\text { within } \\
\text { the past } \\
5 \text { years }\end{array}$ & $\begin{array}{l}\text { More } \\
\text { than 5 } \\
\text { years } \\
\text { ago }\end{array}$ & Never \\
\hline Bad weather conditions & $4.3 \%$ & $55.9 \%$ & $30.8 \%$ & $3.2 \%$ & $5.7 \%$ \\
\hline $\begin{array}{l}\text { Industrial strike action somewhere on the } \\
\text { transport system }\end{array}$ & $0.9 \%$ & $13.7 \%$ & $28.6 \%$ & $21.1 \%$ & $35.7 \%$ \\
\hline Road works & $42.2 \%$ & $30.6 \%$ & $12.6 \%$ & $4.1 \%$ & $10.5 \%$ \\
\hline $\begin{array}{l}\text { Accident or mechanical failure on public } \\
\text { transport }\end{array}$ & $12.8 \%$ & $23.3 \%$ & $21.8 \%$ & $14.4 \%$ & $27.6 \%$ \\
\hline $\begin{array}{l}\text { Having to care for a friend or relative } \\
\text { (including children) }\end{array}$ & $8.6 \%$ & $19.0 \%$ & $16.3 \%$ & $12.4 \%$ & $43.7 \%$ \\
\hline At least one of the above & $50.7 \%$ & $35.8 \%$ & $16.3 \%$ & $9.7 \%$ & $3.8 \%$ \\
\hline
\end{tabular}

(N=2 700 (weighted)) 
Figure 2. Types of events that caused the most disruption

(open question on Six City Survey, N=1 782 (weighted))

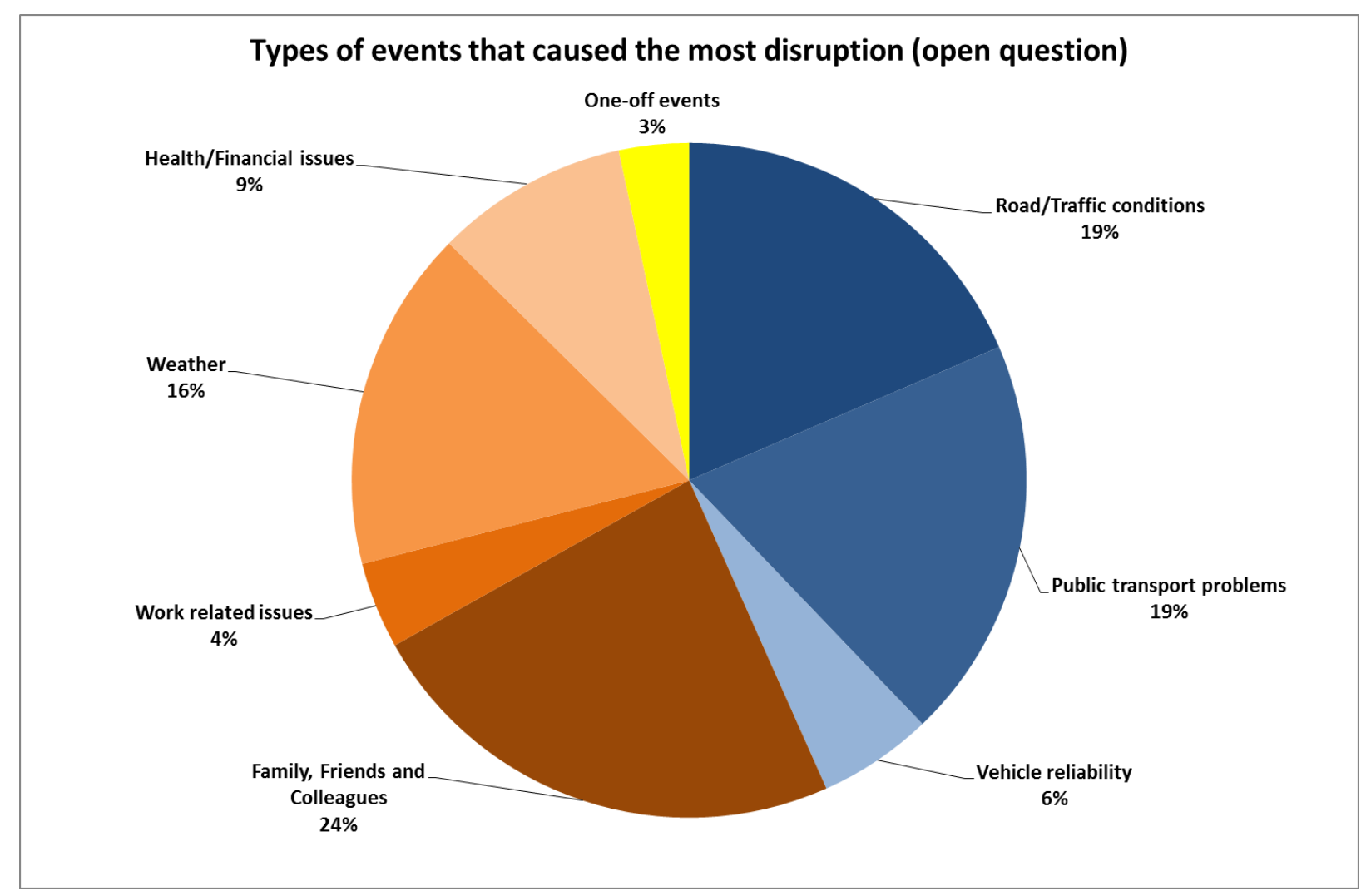

Finding data on disruption at the system level is more difficult. However, the UK rail industry does report this information, partly because of the regulatory mechanisms in place around the vertical separation between network operator and various train operating companies, which requires a very formalised process of examining the causes of delays to rail users. Over the period 2006/07 to 2014/15 compensation payments to the operators attributed to weather reached more than GBP 50m per annum. There were significant impacts on train performance "from the severe weather events during 2007, 2012 and 2013 from rainfall, and 2009 and 2010 from snowfall. In terms of the proportion of delay minutes, weather and seasonal events on average caused $12 \%$ of all delays experienced during this period." (Network Rail, 2015: 9).

Again, whilst significant and highly concentrated in time when they do occur, weather events still only account for $12 \%$ of all delays. Put another way, $88 \%$ of delays on the rail network are not weather resilience-related and justifying resilience expenditure needs to be seen in this context. Over time, of course, climate projections suggest there will be increased risks of weather related events. This also seems to be understood by the public. In our survey of areas affected by flooding, $66 \%$ of respondents agreed that disruption to transport systems was going to increase in the future with only $6 \%$ disagreeing with that. 


\section{For short-run disruptions there is a lot of adaptive capacity}

The remaining data on which this briefing paper is based relates to data collected during disruptive events lasting days and weeks rather than months. Whilst they do not cover disasters, the adaptations nonetheless take place over significant time periods and are representative of many disruptions to infrastructure where temporary loss and damage rather than complete destruction is found. In such circumstances we find a very significant range of behavioural responses, only some of which have traditionally been measured.

Focussing initially on employment, there exists a significant potential to adopt more flexible working arrangements during periods of disruption. This includes working from home, working flexible hours and reallocating tasks within teams or across offices.

In Edinburgh, during the Forth Road Bridge Closure in December 2015, there was a headline reduction in the number of days people travelled to work of 0.4 days per person per week. Three-quarters of this was offset by home working. The remainder may be explained by greater use of flexible working arrangements such as flexi-time to work more intensively on days when travel was made (14\% of respondents reported reducing the frequency of work trips) although $11 \%$ of respondents also reported cancelling at least one commute trip during the closure. The largest reduction was in people travelling to work five days a week which decreased from $63 \%$ to $51 \%$ of commuters.

Similar adaptations were revealed during the winter-weather and flooding disruptions studied. Table 2 shows the range of behavioural response for work and business travel during the winter weather survey and on day one and then subsequent days from the flooding survey.

The winter weather event appears to have had greater impacts on work and business travel due to its coverage of many routes at a regional scale. In addition, $80 \%$ of the respondents with children had to cancel their work trips because local schools were closed and they had to take on childcare responsibilities, irrespective of the safety and availability of their routes to work.

Very few commute and business trips are cancelled due to flooding. Although effects are small, there is less cancellation in commute trips in particular beyond the initial day of uncertainty. Again, there is more rearrangement and conducting of activities from home or in other places than there is cancellation of commute and business activities.

Table 2. Impacts of disruptions on work and business journeys

\begin{tabular}{|c|c|c|c|c|c|c|c|}
\hline Activity & $\begin{array}{l}\text { Delayed } \\
\text { start }\end{array}$ & Postponed & Cancel & $\begin{array}{l}\text { New } \\
\text { destination }\end{array}$ & $\begin{array}{l}\text { Conducted } \\
\text { at home }\end{array}$ & Other & $\mathbf{n}$ \\
\hline \multicolumn{8}{|l|}{ Commute } \\
\hline Winter & $49 \%$ & $8 \%$ & $41 \%$ & $2 \%$ & $12 \%$ & $5 \%$ & 974 \\
\hline Flood day 1 & $29 \%$ & $5 \%$ & $9 \%$ & $3 \%$ & $3 \%$ & $3 \%$ & 627 \\
\hline Flood beyond day 1 & $27 \%$ & $5 \%$ & $6 \%$ & $3 \%$ & $4 \%$ & $3 \%$ & 629 \\
\hline \multicolumn{8}{|l|}{ Business } \\
\hline Winter & $21 \%$ & $41 \%$ & $41 \%$ & $2 \%$ & $5 \%$ & $4 \%$ & 126 \\
\hline Flood day 1 & $10 \%$ & $8 \%$ & $6 \%$ & $3 \%$ & $1 \%$ & $0 \%$ & 567 \\
\hline Flood beyond day 1 & $10 \%$ & $7 \%$ & $5 \%$ & $4 \%$ & $2 \%$ & $1 \%$ & 566 \\
\hline
\end{tabular}


Turning to non-work trips (see Figure 3), we find that reductions in the frequency and changes of the location on non-work trips are the most common responses although significant amounts of cancellation are also evident.

Figure 3. Non-work trip responses during disruptions

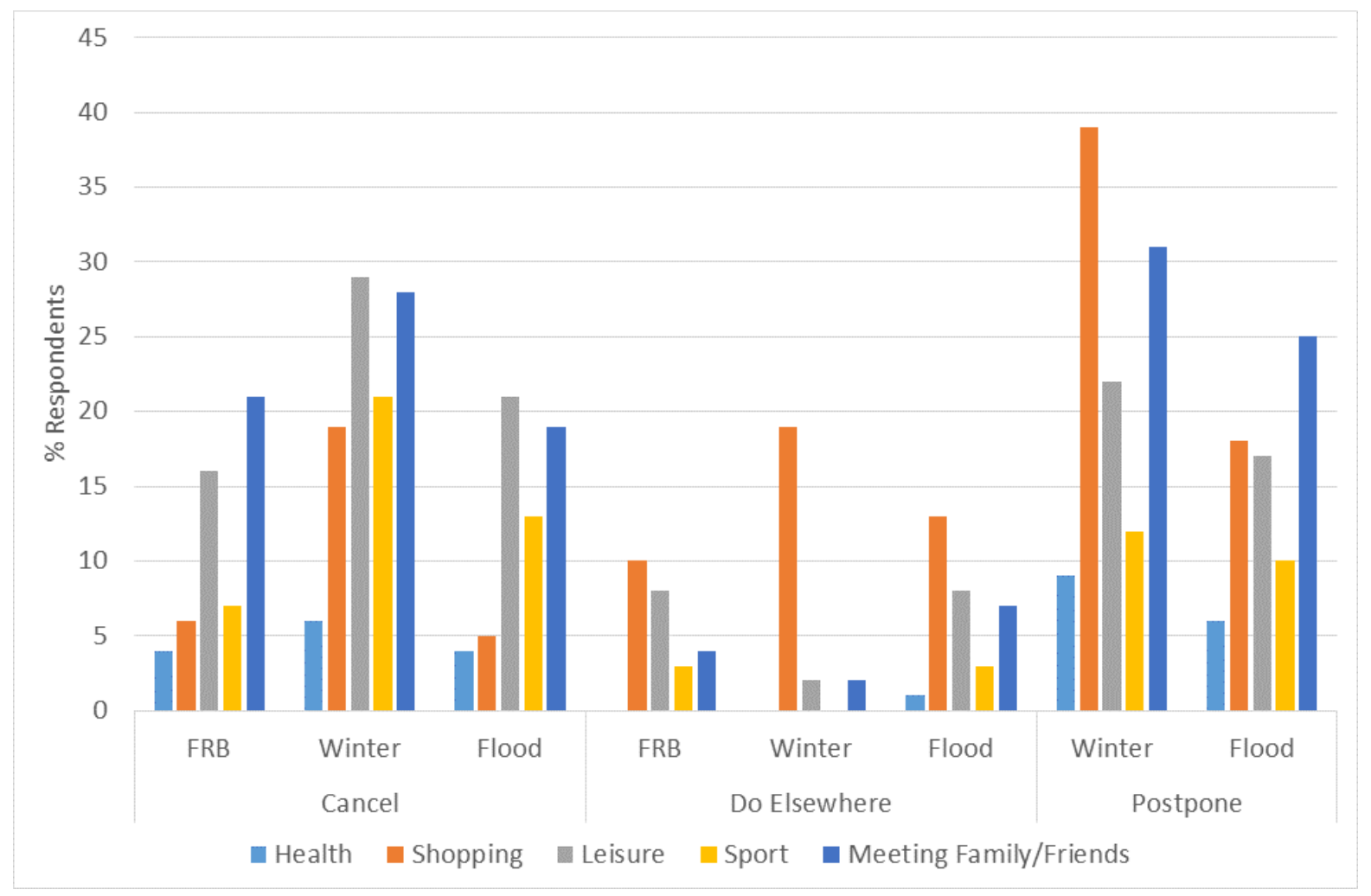

When interpreting changes to non-work activities there are several factors to consider. First, where people are continuing to travel to work and the journey times are longer than is normally the case, then there is less free time in the evening to make non-work trips. Second, the activities themselves may have been affected (e.g. outdoor sports). Beyond this, there seems to be significant shifting of destinations for shopping, typically to more local food shopping and to alternative and more easily accessible non-food shopping. There is also evidence of delaying shopping by a day or two to avoid travelling in bad conditions.

There is a tendency in policy and appraisal to treat non-work trips as less economically important than work trips and certainly for the focus of any adaptive actions by governments and operators to focus on the peak. Many leisure trips are however fundamental to the tourism and entertainment industries, so whilst cancellation may have a small direct personal welfare loss for the traveller it may have a more direct impact on some businesses. In addition, a range of trips have significant societal value. Around $4 \%$ of health appointments were cancelled and 6 to $9 \%$ were postponed which has direct costs to the health care system as well as potential impacts to those missing or delaying treatment. Some people have critical on-going treatments and must travel anyway, often at great personal stress.

We have also interviewed people very negatively affected by missing special events such as funerals and weddings which cannot be rescheduled. Many people visit family and friends as part of caring responsibilities and do not see these trips as the kind of "discretionary" travel they are often assumed to be. Our data suggests that greater attention should be given to a holistic understanding of the 
impacts of disruption on activities and wellbeing. Here it seems likely that traditional estimates of "value of time" do not hold as they are determined from asking about responses in circumstances that are experienced more often (such as a cancelled train).

Finally in this section we examine impacts of events on mode shifting and re-routing. The circumstances of each disruption and the availability and capacity of alternative modes and routes to cope with substantially different patterns of travel will vary from place to place. The loss of infrastructure such as a bridge in a rural setting may lead to very significant diversionary journey times as there are limited alternatives (Guiver, 2011). However, there can be lengthy diversions in urban areas where networks are already at capacity which significantly extend journey times.

Distance can be a proxy for the likelihood of being exposed to weather events (all else being equal). As Figure 4 (from the flooding survey) shows, shorter journeys were more likely to just carry on as before whilst longer journeys were more likely to shift to another form of transport and/or be rescheduled. In addition, it is notable that short trips were less likely to be rearranged.

In both the flooding and Forth Road Bridge closure research we found very substantial increases in journey times. In the case of flooding in York, travellers reported journeys which would typically take 20 minutes becoming sometimes up to 90 minutes. This was a dynamic and changing situation and people reported not being sure how long it would take them to get places. In Edinburgh, where a clear diversionary route was set up and actively promoted by the roads authorities, journey times by car doubled from 45 minutes to 90 minutes and by bus from 66 minutes to 102 minutes. The key point for understanding the economic impacts of these journey time changes is that they are not small increments. Much understanding of delay values of time and unreliability comes from looking at relatively small changes in the context of daily journeys (e.g. the late train or worse than usual congestion). We return to the significance of this for understanding how to value disruption later. 
Figure 4. Mode shift and cancellation by distance travelled during flooding

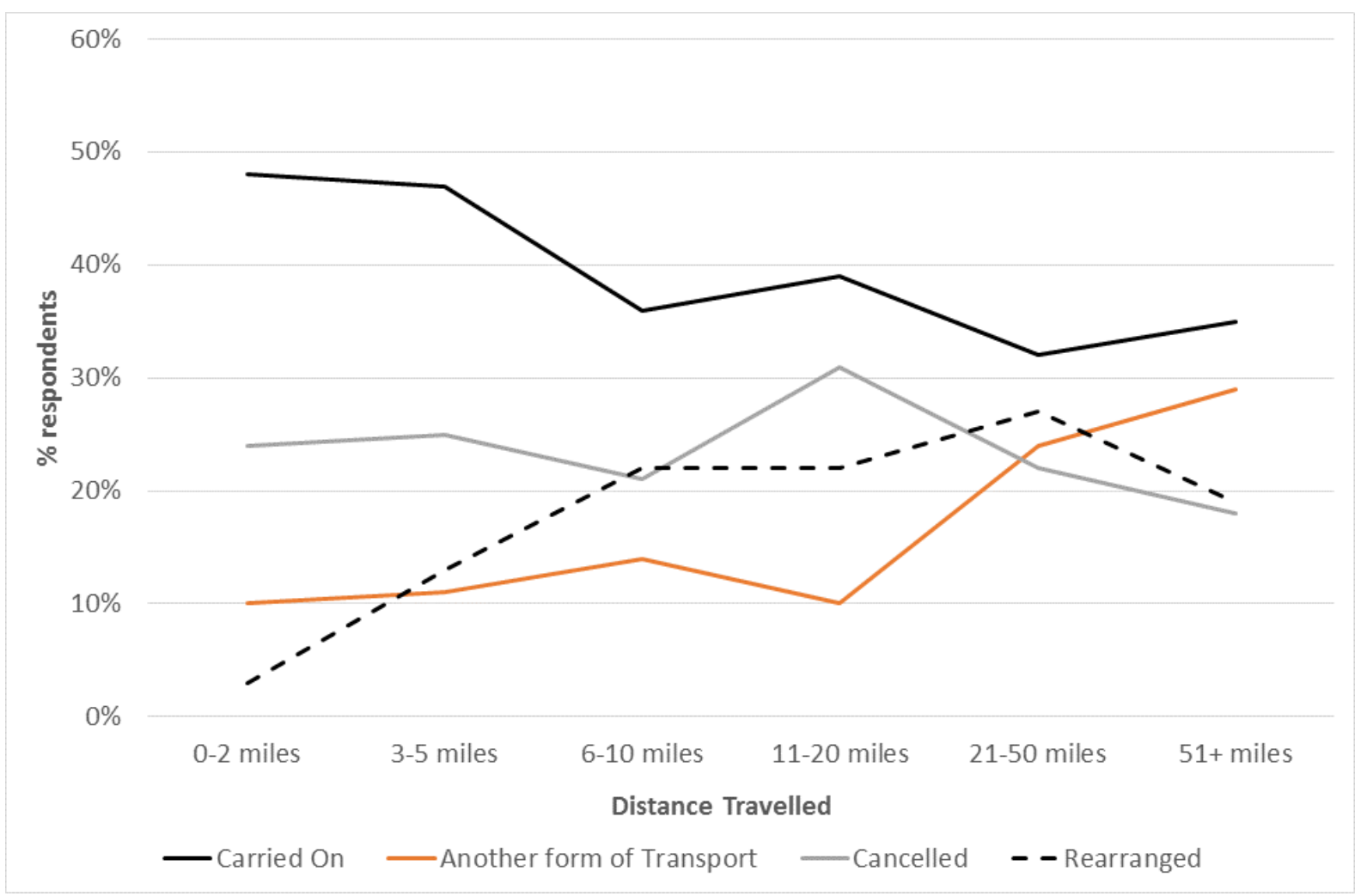

In Edinburgh, a rail link remained open and extra services were provided which attracted a significant proportion of people who used the road bridge by car or bus before the closure. However, modal transfer points were challenging for travellers, with over $65 \%$ of users reporting parking provision at train stations as poor or very poor, with an equivalent figure of $76 \%$ for bus users accessing the stations via bus. This is a key issue for the provision of both special alternative services during disruption, or for users seeking to use a different existing mode/service. If transport infrastructure and services are operating at or close to capacity in a "normal" situation then it is likely that they will not cope effectively with an additional demand surge resulting from disruption. Insufficient parking spaces and limited boarding capacity mean additional service provision needs to be well planned in advance, along with detailed consideration of how people will actually access the extra services in practice.

In York, where the road network has little spare capacity, the loss of even small amounts of infrastructure can cause gridlock relatively quickly. Here, where many journeys are relatively short, cycling provides an easy alternative. However, parts of the cycle infrastructure are also prone to flooding so a more resilient cycle infrastructure and clear routing for flood days is necessary if this is to fulfil its potential. We revisit the measures that can be taken in the Section on Implications. However, it seems certain that reconfiguring activities to take as many trips off the network as possible during the peak is critical to making the most of any modal response strategies. 


\section{Evidence on what supports adaptive capacity}

There are a number of elements which appear to correspond either with greater reported adaptive capacity or which are indicative of greater adaptive capacity within the system.

The first element to consider is experience. There is evidence (see Table 3 for some example data) that those people who experience disruptions more frequently are better able to adapt as exhibited by greater percentages working from home and greater percentages using other modes of transport. Work in the City of York around flooding showed that those who were new to York since the last big flood in 2000 were prone to make poor choices about where would be affected and how badly, thus setting off on journeys which were ultimately very time consuming.

Table 3. Responses based on experience of previous flooding disruption (all activities)

\begin{tabular}{|l|r|r|r|r|r|r|r|r|}
\hline Activity & $\begin{array}{l}\text { Carried } \\
\text { on }\end{array}$ & $\begin{array}{l}\text { Conducted } \\
\text { at home }\end{array}$ & $\begin{array}{l}\text { Another } \\
\text { form of } \\
\text { transport }\end{array}$ & Cancelled & Rearranged & $\begin{array}{l}\text { Someone } \\
\text { else }\end{array}$ & $\begin{array}{l}\text { New } \\
\text { destination }\end{array}$ & Other \\
\hline 0 times & $37 \%$ & $5 \%$ & $15 \%$ & $24 \%$ & $19 \%$ & $1 \%$ & $11 \%$ & $4 \%$ \\
\hline $\begin{array}{l}1-2 \\
\text { times }\end{array}$ & $44 \%$ & $10 \%$ & $14 \%$ & $23 \%$ & $20 \%$ & $3 \%$ & $6 \%$ & $9 \%$ \\
\hline $\begin{array}{l}3-6 \\
\text { times }\end{array}$ & $38 \%$ & $11 \%$ & $19 \%$ & $24 \%$ & $19 \%$ & $4 \%$ & $7 \%$ & $8 \%$ \\
\hline $\begin{array}{l}7+ \\
\text { times }\end{array}$ & $27 \%$ & $12 \%$ & $25 \%$ & $26 \%$ & $19 \%$ & $4 \%$ & $5 \%$ & $7 \%$ \\
\hline
\end{tabular}

A key element of the ability to switch forms of transport for different journeys is a prior understanding of those transport options and how to use them. Experience of travelling by different forms of transport is therefore also a key part of adaptive capacity within the system. Whilst in many developed countries the car is the dominant mode, many people are in fact multi-modal across the week (Heinen and Chatterjee, 2015). The survey of six cities identifies distinct clusters of travellers with different levels of multi-modality (Figure 5). Here, for example, whilst the red circle represents almost exclusive car use, the blue represents a mix of car use and alternative (walk and cycle) modes and the green a mix of public transport and walk and cycle. The research found that the higher the car use, the lower the expectation of disruption to happen frequently compared to other mode users. But people who rely on active modes are the least likely to say disruption has a major impact on their lives. Policies which promote multi-modality in daily travel for health, congestion or environmental reasons should support the skills needed for greater travel flexibility during moments of disruption. 
Figure 5. Ternary plot of mode share across all trips

(Six City Survey, N= 2 700)

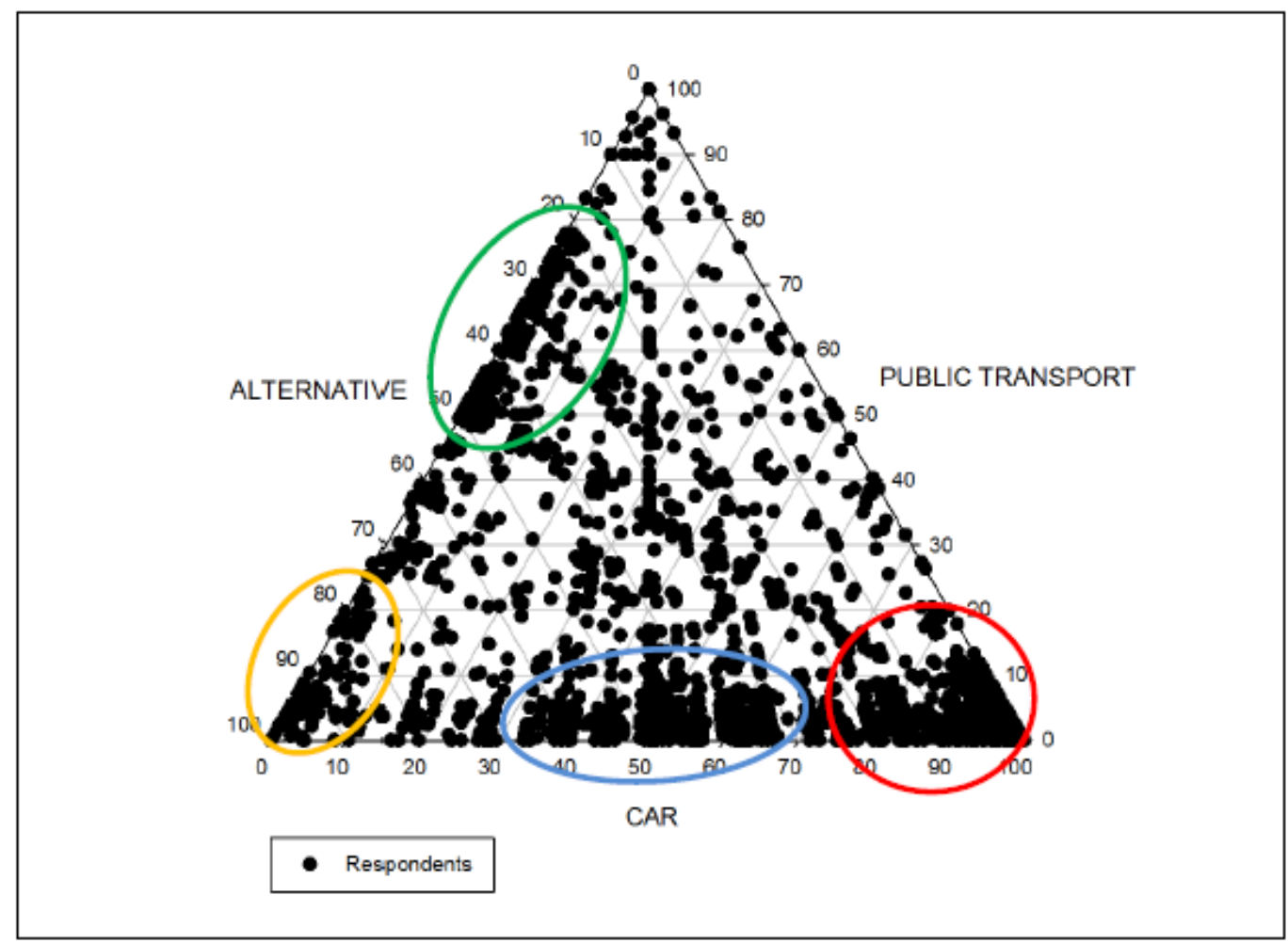

The role of workplaces and the expectations that they set out for their workers also influences the extent to which flexibility in travelling to work can be adopted. Our data show that the level of flexibility apparent varies substantially between job types. The potential to switch some employees to home working and thus remove some commuting traffic during periods when transport networks are operating over capacity due to the loss of some infrastructure therefore offers a potentially significant benefit to those who have to continue to travel.

Table 4. How the employer attitude to changing working patterns impacts travel choices

\begin{tabular}{|l|l|c|c|}
\hline \multirow{2}{*}{ Survey } & \multirow{2}{*}{ \% Response } & \multicolumn{2}{|c|}{ Employer attitude } \\
\cline { 3 - 4 } & & $\begin{array}{c}\text { Very } \\
\text { accommodating }\end{array}$ & $\begin{array}{c}\text { Very } \\
\text { unaccommodating }\end{array}$ \\
\hline \multirow{2}{*}{ Flooding } & \% Carried On & 55 & 67 \\
\cline { 2 - 4 } & \% Work From Home & 12 & 0 \\
\hline \multirow{2}{*}{ Winter weather } & \% Carried On & 30 & 40 \\
\cline { 2 - 4 } & \% Work From Home & 24 & 18 \\
\hline
\end{tabular}

There is clearly the potential to do more to maximise the capability of employees to work from home. As with the example of prior knowledge of different transport modes we identify above, this is easier if it is something which sometimes happens anyway in the course of "normal" work, as then employees have appropriate/sufficient equipment, communications options and working protocols near at hand to make it possible. During the Forth Road Bridge closure, $84 \%$ of respondents reported home working being possible. Of these $84 \%, 38 \%$ of employers were supportive of home working (a great deal or quite a bit) but $42 \%$ were not supportive of home working. $90 \%$ of respondents reported flexible 
working being possible (e.g. longer hours on some days). 57\% of employers were supportive of flexible working (a great deal or quite a bit) and only 18\% were not supportive of flexible working. Even for those with no ability to work from home, different shift arrangements can be implemented to increase the intensity of each work trip and reduce the total trip volume.

There is also evidence that strong social networks are important during periods of disruption. There is the potential for role reallocation as a means of overcoming the constraints of longer journey times for example and this is used for $3 \%$ to $4 \%$ of journeys across the flooding and winter weather disruptions. This is easier within a household with two adults, whilst lone parents reported feeling particularly vulnerable to disruptions due to tight schedules and a reliance on favours from others if things went wrong. Similarly, additional out-of-pocket expenses may be incurred if public transport season tickets cannot be used or if car drivers switch for one or two days to public transport. Lower income travellers will therefore have fewer affordable response options, especially as short notice/immediate travel tickets are premium priced.

\section{Longer-term behavioural impacts}

For the vast majority of travellers, short periods of disruption are tolerated or coped with and then, when the infrastructure or services return to their previous state, they return to their previous patterns. As Graham and Thrift (2007) suggested however, periods of disruption are also times where adaptation and innovation occur.

During the Forth Road Bridge Closure travellers were asked about the likelihood of returning to their previous behaviours:

- $8 \%$ of travellers reported being not at all or very unlikely to return to their previous frequency of travel;

- $\quad 7 \%$ reported being not at all or very unlikely to return to the previous timing of travel;

- $6 \%$ reported being not at all or very unlikely to return to the previous mode of travel.

Our suggestion here is not that such events can be seen to be catalysts for behaviour change per se. However, they do reveal that at any point in time some people have settled into a travel rhythm and frequency of travel that might not actually be optimal for them. As companies and individuals are forced into finding ways of accommodating disruption, new and better ways of working can be created. When the infrastructure is put back in working order not all of the flows that previously used that infrastructure will necessarily return to use it in the same way or with the same intensity.

More generally, the realisation that significant percentages of people can think through changing their travel behaviour (in challenging circumstances) suggests that there exists the potential for more planned behaviour change interventions to shift travel demand on the network. We note however that the long-term impacts of such interventions are not well understood (Parkes et al., 2016). In a similar way to the development of multi-modal skills over time, developing experience of more flexible working will enable that strategy to be more effectively deployed in a range of circumstances including infrastructure disruption. The smart city of the future and smart resilience responses should take seriously the potential to adapt demand on a daily basis through effective management. 


\section{Information}

There is recognition amongst governments, network operators and service providers about the importance of communication during periods of disruption: "It is obviously very important that transport and network operators communicate with passengers and other stakeholders as clearly as possible on how services are being affected by the weather, or as a result of weather induced damage to infrastructure. Achieving this with maximum effect requires an understanding of the available information channels and how those are being used by travellers and freight customers." (DfT, 2014: 34)

Our work across all of the surveys suggests that communication must continue to be through a wide range of channels. Whilst there are differences between how different groups access information and how they use them (Table 5), it is the large range of information channels which are accessed which stand out and which, therefore, raise challenges of the provision of consistent information and guidance across modes and areas.

Table 5. Most accessed information sources by age group (Forth Road Bridge)

\begin{tabular}{|l|l|l|l|l|l|}
\hline Rank & $\mathbf{1 6 - 2 9}$ years & $\mathbf{3 0 - 3 9}$ years & 40-49 years & $\mathbf{5 0 - 5 9}$ years & 60-69 years \\
\hline 1 & TV & TV & TV & TV & TV \\
\hline 2 & Train website & Train website & Radio & Radio & Radio \\
\hline 3 & Radio & Radio & Train website & Train website & Train website \\
\hline 4 & Facebook & Facebook & $\begin{array}{l}\text { Government } \\
\text { website }\end{array}$ & $\begin{array}{l}\text { Government } \\
\text { website }\end{array}$ & Newspaper \\
\hline 5 & $\begin{array}{l}\text { Government } \\
\text { website }\end{array}$ & $\begin{array}{l}\text { Government } \\
\text { website }\end{array}$ & Facebook & Newspaper & $\begin{array}{l}\text { Government } \\
\text { website }\end{array}$ \\
\hline 6 & $\begin{array}{l}\text { Official Twitter } \\
\text { feeds }\end{array}$ & $\begin{array}{l}\text { Official Twitter } \\
\text { feeds }\end{array}$ & Newspaper & Facebook & Bus website \\
\hline
\end{tabular}

There is a greater prevalence of social media use in the under 40s, with Facebook and Twitter most popular in this age group. Twitter was less used by over 40s and Facebook by over 60s. As well as considering which channels people access, it is essential to understand what they found useful. The three sources with the highest scores of "very helpful" across all respondents were: Radio news (18\%); Official Twitter feeds (16\%) and Facebook (15\%).

When looking only within those people that use each source we see a similar picture. Overall helpfulness (very helpful or helpful) from users of that source were: Official twitter (75\%), Facebook (73\%), Radio news (71\%), Un-official Twitter (66\%) and Train company website (66\%).

This suggests very strongly that whilst users will access lots of sources of information, the more dynamic sources of information are deemed to be the most helpful with other channels such as TV, newspaper and government websites being used perhaps more for context. This was found also in the response to Hurricane Sandy in New York City where posting images of flooded subway stations and closed facilities was used to reinforce traditional text based warnings of infrastructure closures (Kaufman et al., 2012). 


\section{Implications for resilience planning}

This briefing paper has marshalled evidence from several studies collecting data on travel and wider activity system responses to disruptive events. It represents unique analysis that suggests some new implications for resilience planning that go beyond the substantive work already underway on the design of more resilient infrastructure. The key implications for agencies, operators and governments are set out below.

\section{A smart resilience strategy is a combination of transport and non-transport responses}

People travel to take part in activities. Focussing on the transport system response is important (discussed further below) but is not sufficient. Interventions and actions should address how to reduce the need to travel and the frequency of travel, to shift demand away from the peak and change the destinations people are accessing. This reduces the scale of the transport management task whilst also continuing to support a well-functioning economy. Measures could include:

- Reliable ubiquitous broadband in communities likely to be affected by road closures;

- Pro-active company policies to reduce the proportions of staff physically accessing work on special weather days;

- Temporary shifts to school opening hours and/or pre and after school care to enable parents to avoid travelling in the peak;

- Work with supermarkets to offer discounts for home shopping;

- Clear communication about facilities which are closed as a result of bad weather;

- Opening up spare office space for colleagues from elsewhere in the business or from other local companies (see Kaufman et al., 2012 following Hurricane Sandy);

- Reallocating medical appointments to the nearest reachable service and rescheduling some appointments (see Guiver, 2011);

- Postponing non-urgent public sector meetings and travel and encouraging the private sector to do the same (see Parkes et al., 2016).

\section{Better targeted information is urgently needed}

Our work showed that dynamic, real-time information sources are perceived as more helpful than alternative sources of information about disruption. It is also now understood that including pictures of infrastructure problems helps to communicate to the public how significant the delays or how long term the problems are likely be. Nonetheless, there is not much good practice written down about how to more 
intelligently target information at travellers so that they are fully aware of the likely journey times they face and the alternative options that exist for them. This is critically important because our evidence suggests that many people will not have experienced these events before and, even amongst more experienced citizens, poor choices are being made which lead to very extended journey times which would otherwise be avoided. Some potential avenues for investigation:

- There needs to be greater geo-precision of problems on the network. During flooding static signs are often used but not always trusted (or up to date) and sometimes only encountered late in the route choice process;

- Floodline information reports river levels but this does not correspond to actionable information for travellers who need to know which routes will become affected. There is scope for better integration of the water and road network management teams;

- Smart phone technology should allow users to access route-specific information and to be informed about favourite routes. However, user literacy with these technologies is not yet high enough. Better data on the evolution of journey times is also needed if people are to avoid setting off on journeys which it subsequently becomes difficult to finish or return from;

- Because of the variety of information sources, there needs to be co-ordination amongst the different providers to ensure that consistent advice is being given (e.g. if advice is being given not to travel to the rail station then refunds on pre-booked tickets should be assured).

\section{The skills needed for resilience response are the skills needed to promote more sustainable travel and these need to be put together}

During a period of disruption we are essentially asking society to quickly adapt and begin to move around by different modes, at different times of day, or to move less. These are all core messages in thinking about travel behaviour change more generally. We know that travellers who are unfamiliar with multiple modes find it more difficult to change. We know that working from home is easier during disruptions if you already have the kit and processes to support doing it. Adaptive capacity is an important part of the response to disruptions and it can be developed. One measure of the vulnerability of cities is the extent to which their networks are overly dependent on one form of transport and the extent to which that form of transport is itself subject to disruption. This suggests the following types of intervention will support better responses during disruptions (see also www.fleximobility.solutions):

- A strong programme of workplace travel planning;

- The use of events and incentives (e.g. Christmas Shopping, car free days, free tickets) to develop familiarisation with public transport for non-users;

- The presence of a good cycle networks (which also have flood resilience);

- Personalised travel planning to raise awareness of options. 


\section{The economic impacts of disruptive events need re-examining as does the basis for the appraisal of investments for resilience}

It can be very difficult to justify expenditure on the grounds of resilience for some parts of the network because such events can be rare but high impact. However, across the life of the assessment period of sometimes up to 60 years, the benefits of avoiding such events can be small relative to the daily benefits of congestion reduction and environmental improvement for example. Whilst the ideal is to design resilience into all new schemes, the reality is that large parts of our networks are ageing and already exposed to these risks and the risks are growing. Our networks will be exposed to an increasing number of weather related events in future. The case for intervening needs to be made, we suggest, on a clearer whole system understanding of the impacts of these events and it is necessary to look at the decision-making toolkit which underlies this. In particular our evidence shows that:

- There are very large increases in journey times and complete losses of modes during some events which violates the traditional calculation of costs of disruption;

- Disruptive events play out over time and yet we have no tools available to us which explain how significant delays or loss of service are in the immediate aftermath of an event, in the days that follow or over longer time periods. There is little therefore to guide assessments of the cost-effectiveness of alternative provision or to compare the costs of several short events of two days compared with a loss of two weeks or a month;

- Many of the impacts are well beyond the transport market (closure and damage of buildings, schools, facilities, farmland). Transport is here a secondary and not primary market. To understand the real impacts of these events would require the adoption of multiple market models (e.g. general equilibrium modelling);

- Strategies of risk minimisation are evident: for example households and businesses keeping additional stocks for the disruptive events or adults who work less than they otherwise might to ensure childcare arrangements are robust. These examples of risk-averse behaviour imply firstly the likely existence of option values and secondly a potential shift in the long-run supply curve with disruption (e.g. increased inventories both for households and businesses). These shifts are not well understood and not factored into decision-making.

Whilst it is not possible in this report to provide a definitive statement about the absolute importance of these factors (the content of each event matters and some of the data has not been collected systematically) there is a risk that current methods are over estimating some aspects of short-run impacts (events of a small number of days) where adaptation is more feasible and underestimating the impacts of longer run events or events which occur on multiple occasions. 


\section{Bibliography}

Begg, D., Cherry, J., DeCosta, B., Felder, J., Field, M., Hunter, J. Loney, M., Sigler, M., Sutton, R., Swan, M., Williams, R., Quarmby, D. and Langsdale, P. (2011), Report of the Heathrow Winter Resilience Enquiry, BAA.

DfT (2014), "Transport Resilience Review: A review of the resilience of the transport network to extreme weather events", Cm8874, Department for Transport, London, July 2014.

EC (2013), Adapting infrastructure to climate change, European Commission SWD (2013) 137 final, Brussels, April 2013.

Figliozzi, M. and Zhang, Z. (2010), A Study of Transportation Disruption Causes and Costs, 89th Annual Transportation Research Board Meeting, Washington D.C.

Graham, S. and Thrift, N. (2007), "Out of order" Theory, Culture \& Society, Vol. 24, pp. 1-25.

Guiver, J. (2011), “Travel adjustments after road closure: Workington”, Proc. 43rd Annual Universities' Transport Studies Group Conference, Milton Keynes, 3-5 January.

Heinen, E. and Chatterjee, K. (2015), "The same mode again? An exploration of mode choice variability in Great Britain using the National Travel Survey", Transportation Research Part A, Vol. 78, pp. 266-282.

Holling, C. (1986), "Engineering Resilience versus Ecological Resilience", in: Foundations of Ecological Resilience, Island Press.

ITF (2015), "Adapting Transport Infrastructure to Climate Change: How to Protect Assets Against Increased Risks from Extreme Weather", International Transport Forum, Discussion Paper, November 2015. http://www.itf-oecd.org/sites/default/files/docs/cop-pdf-05.pdf.

Kaufman, S., Qing, C., Levenson, N. and Hanson, M. (2012), "Transportation During and After Hurricane Sandy", Rudin Center for Transportation, NYU Wagner Graduate School of Public Service.

Laird, J., Marsden, G. and Shires, J. (2014), "Evaluating transport and land-use interventions in the face of disruption", Universities Transport Studies Group Conference, Newcastle, January.

Mattson, L-G and Jenelius, E. (2015), "Vulnerability and resilience of transport systems: A discussion of recent research", Transportation Research Part A, Vol. 81, pp. 16-34.

Network Rail (2015), "Climate Change Adaptation Report 2015", Network Rail, London.

Parkes, S.D., Jopson, A.F. and Marsden, G. (2016), "Understanding travel behaviour change during mega-events: Lessons from the London 2012 Games", under review Transportation Research Part A. 
Quarmby, D. (2010)," The Resilience of England's Transport Systems in Winter: An Independent Review (Final Report)". London: Department for Transport, HMSO.

Vollmar, H. (2013), The Sociology of Disruption, Disaster and Social Change Punctuated Cooperation, Cambridge University Press

Volpe (2015), "International Practices on Climate Adaptation in Transportation: Findings from a virtual review", Synthesis Report for the Federal Highways Administration, Washington D.C., January 2015.

Wardman, M. (2001), "A review of British evidence on time and service quality valuations". Transportation Research Part E, Vol. 37, pp. 107-128.

Wesemann, L., Hamilton, T., Tabaie, S. and Bare, G. (1996), "Cost-of-delay studies for freeway closures caused by Northridge earthquake". Transportation Research Record, Vol. 1559, pp. 67-75.

Xie, F., and Levinson, D. (2011), "Evaluating the effects of the I-35W bridge collapse on roadusers in the twin cities metropolitan region". Transportation Planning and Technology, Vol. 34(7), pp. 691-703.

Zhu, S. and Levinson, D.M. (2010), "A Review of Research on Planned and Unplanned Disruptions to Transportation Networks", 89th Annual Transportation Research Board Meeting, Washington D.C. 
